\title{
Molecular characterization of a Chinese variant of the Flury-LEP strain
}

\author{
Linzhu Ren
}

\begin{abstract}
The entire genome of rabies virus vaccine strain Flury-LEP-C, a Chinese variant of the rabies virus vaccine strain FluryLEP, was sequenced. The overall length of the genome of Flury-LEP-C strain was 11924 nucleotides (nt), comprising a leader sequence of $58 \mathrm{nt}$, nucleoprotein (N) gene of $1353 \mathrm{nt}$, phosphoprotein (P) gene of $894 \mathrm{nt}$, matrix protein (M) gene of 609 nt, glycoprotein (G) gene of 1575 nt, RNA-dependent RNA polymerase (RdRp, L) gene of $6384 \mathrm{nt}$, and a trailer region of $70 \mathrm{nt}$. There was TGAAAAAAA $\left(\mathrm{TGA}_{7}\right)$ consensus sequence in the end of each gene in Flury-LEP-C genome, except $\mathrm{G}$ gene which had a GAGAAAAAAA sequence in the end of the non-coding G-L region. There were AACAYYYCT consensus start signal close to the TGA 7 . Flury-LEP-C has 310 nucleotides more than HEP-Flury in G-L intergenic region. The analysis showed that the residue at 333 of the mature $\mathrm{G}$ protein was Arg, which was reported to be related to pathogenicity. Compared with FluryLEP, there were 19 different amino acids (AAs) in five proteins of FluryLEP-C, including 15 AAs which were identical with corresponding residues of Hep-Flury, and 4 AAs which were neither identical with the residues of FluryLEP nor with the residues of Hep-Flury. The results showed the topology of the phylogenetic trees generated by two protein sequences were similar. It was demonstrated that HN10, BD06, FJ009, FJ008, D02, D01, F04, F02 have a close relationship to CTN-1 and CTN181, and MRV was closely related to Flury-LEP, HEP-Flury and Flury-LEP-C.
\end{abstract}

\section{Findings}

The rabies virus belongs to the Rhabdoviridae family and the Lyssavirus genus. The genome of the rabies virus is a non-segmented, anti-sense, single-stranded RNA which is about 12, 000 nucleotides (nt) long. Viral RNA encodes five major proteins: nucleoprotein (N-protein), phosphoprotein (P protein), matrix protein (M-protein), glycoprotein (G-protein) and RNA-dependent RNA-polymerase (L-protein) [1].

It was reported there were still high rabies cases happened in China, especially in rural China, about 5537 fatalities per year in 80 's, and about 3300 fatalities in 2007 [2-5]. During recent years, most of the research on the control of rabies has concentrated on the development of oral vaccine, including attenuated vaccine and live vectored vaccines. However, these virus strains are still pathogenic for laboratory and wild rodents or wildlife species, and several rabies cases caused by such vaccines have been reported [6,7]. It was reported some rabies

* Correspondence: renlz@jlu.edu.cn

${ }^{1}$ College of Animal Science and Veterinary Medicine, Jilin University, Changchun 130062, China

Full list of author information is available at the end of the article virus in China was closely related to several vaccine strains [8]. The main goal of the present study was to obtain the entire genome sequence of vaccine strain Flury-LEP-C, a Chinese variant of the rabies virus vaccine strain Flury-LEP, including the 3'- and 5'-terminal noncoding regions of the genome. The genome sequence has been compared to the sequences of other vaccine strains used in China and street strains in China available from GenBank. The data obtained from vaccine strain and street strain can lead to a better understanding and more effective strategies to control the spread of rabies.

Here, we obtained the full length genome of Flury-LEP$C$ strain by RT-PCR or RACE similar to the method described by Marston et al. [9]. Using a total of 12 primers (as shown in Table 1), the entire genome of FluryLEP-C strain was amplified as 5 separate overlapping PCR products. The result showed that the full genome of rabies virus strain Flury-LEP-C consists of $11924 \mathrm{nt}$. The full length sequence was submitted to GenBank (GenBank accession numbers FJ577895).

In the full genome sequence of Flury-LEP-C, the leader sequence was $58 \mathrm{nt}$ in length, while trailer sequence was 
Table 1: Primers used for amplification of the Flury LEP strain

\begin{tabular}{|c|c|c|c|}
\hline Designation & Sequence of primers & Length & Location \\
\hline RLM-3' RACE oligonucleotidesa & 5'-GTCGTACTAGTCGACGCGTGGCCTAG-3' & 26 & \\
\hline $\begin{array}{l}\text { 3' RACE complementary } \\
\text { oligonucleotides }\end{array}$ & 5'-GGCCACGCGTCGACTAGTAC-3' & 20 & \\
\hline LEPR1(antisense) & 5'-CAAGAGGGCCCCTGGAATCA-3' & 20 & $2872-2892$ \\
\hline LEPF2(sense) & 5'-TCCAGGGGCCCTCTTGAAGGGGAG-3' & 24 & $2875-2899$ \\
\hline LEPR2(antisense) & 5'-ATGACCGGTCTTCACAGTCTGGTC-3' & 24 & $4881-4905$ \\
\hline LEPF3(sense) & 5'-GTGAAGGCCGGTCATCCTITTGACAATT-3' & 28 & $4888-4916$ \\
\hline LEPR3(antisense) & 5'-CAAGAGACTCGGGCCCAT-3' & 18 & $7836-7854$ \\
\hline LEPF4(sense) & 5'-GATGGGCCCGAGTCTCTTGC-3' & 20 & $7833-7853$ \\
\hline LEPR4(antisense) & 5'-TAACACAAGATCGATCTGTTG-3' & 21 & $9905-9926$ \\
\hline LEPF5(sense) & 5'-CCACTATGAAAGAAGGCAACAGATCGATC-3' & 29 & $9888-9917$ \\
\hline 5' RACE Outer Primer & 5'-CATGGCTACATGCTGACAGCCTA-3' & 23 & \\
\hline 5' RACE Inner Primer & 5'-CGCGGATCCACAGCCTACTGATGATCAGTCGATG-3' & 34 & \\
\hline
\end{tabular}

aThese two oligonucleotides were synthesized according to Marston et al. (2007).

70 nt. All RVs (as shown Table 2) in this study were absolutely conserved over the 12 bases of the genomic 3 '-terminus (Fig. 1) and 5'-terminus (Fig. 2). The sequences of 3 ' leader and 5 ' trailer termini showed exactly complementary for the terminal $11 \mathrm{nt}$ of all RVs, except that MRV and DRV showed different 3'-terminus and 5'-terminus end.
Between the transcription stop and start signals, there was an intergenic sequence (IGS), which was not transcribed into mRNA. The N/P IGS was CT. The P/M IGS was CAGGC, and $M / G$ IGS was CTATT. The IGS between the non-coding $\mathrm{G}-\mathrm{L}$ region and $\mathrm{L}$ gene was 21 nt.

\section{Table 2: Rabies virus referenced in this study}

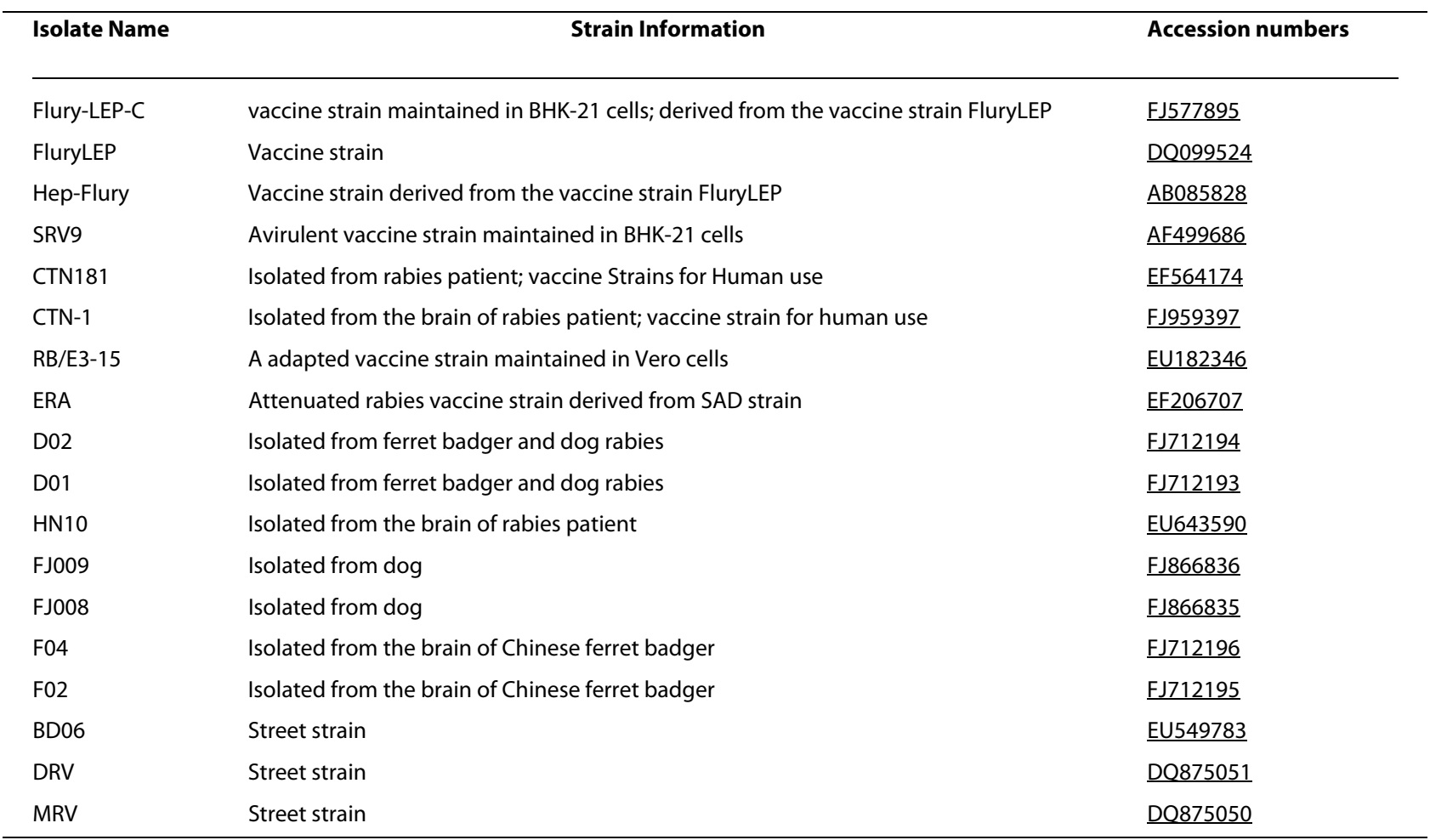




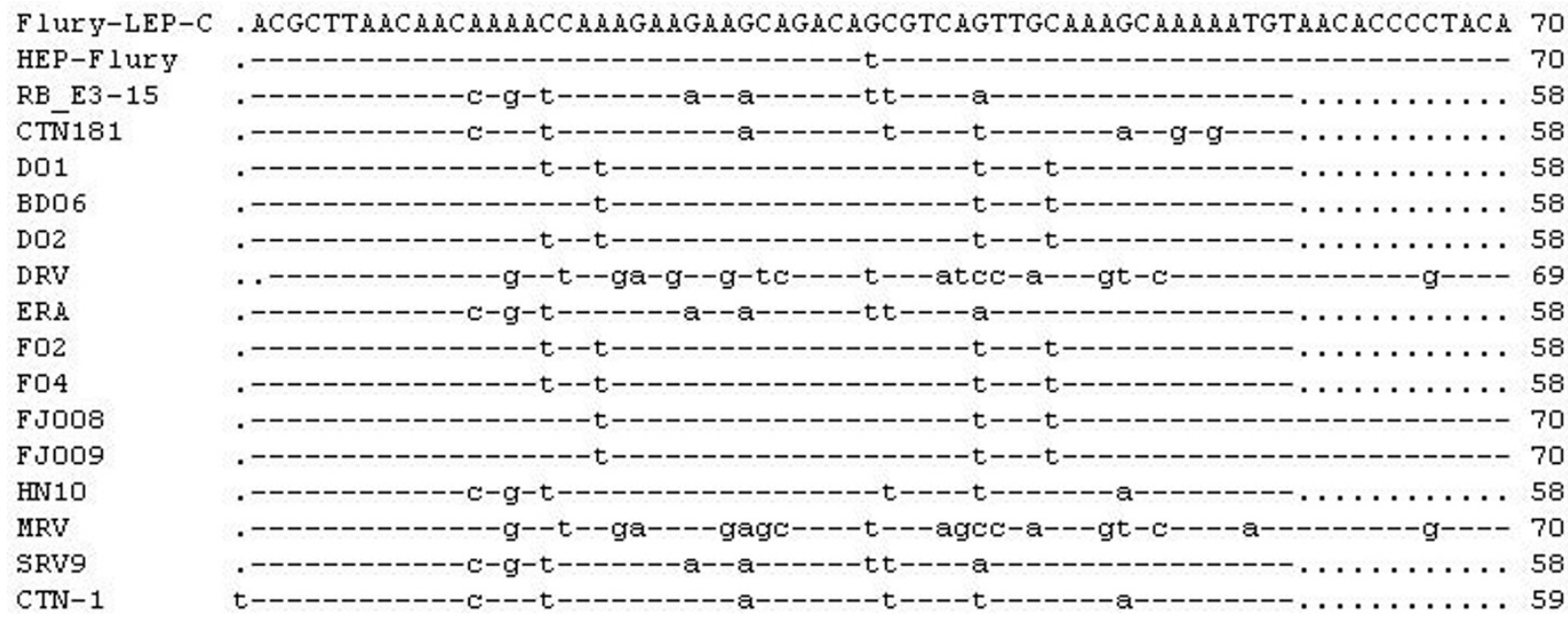

Figure 1 Comparison of 3'-termini of the antigenome (+) sense RNA (in DNA code). 3'-termini of Flury-LEP-C strain and other rabies virus were compared. Only differences from the reference sequences are shown. "-" indicate sequence identity to the reference sequence and a "." indicate missing sequence.

The G-L intergenic region is a non-coding region. It was reported that this region was highly susceptible to random mutations, unrestricted by structure and function requirements or by immunological pressure [10]. Comparison result in this study showed that the G-L intergenic region of Flury-LEP-C has 310 nucleotides more than that of HEP-Flury (Fig. 3), which demonstrate that the non-coding $\mathrm{G}-\mathrm{L}$ region was more prone to mutate. The observation indicates that the region may be used as an insertion site for a marker gene to construct a marker vaccine. However, studies should be undertaken to confirm this hypothesis.

Rabies virus encodes five structural proteins in the order of N-P-M-G-L. The length of five genes of FluryLEP-C strain were 1353 nt, 894 nt, 609 nt, 1575 nt, 6384 nt, respectively. There was TGAAAAAAA $\left(\mathrm{TGA}_{7}\right)$ consensus sequence in the end of each gene in Flury-LEP-C genome, except that $G$ gene had a GAGAAAAAAA

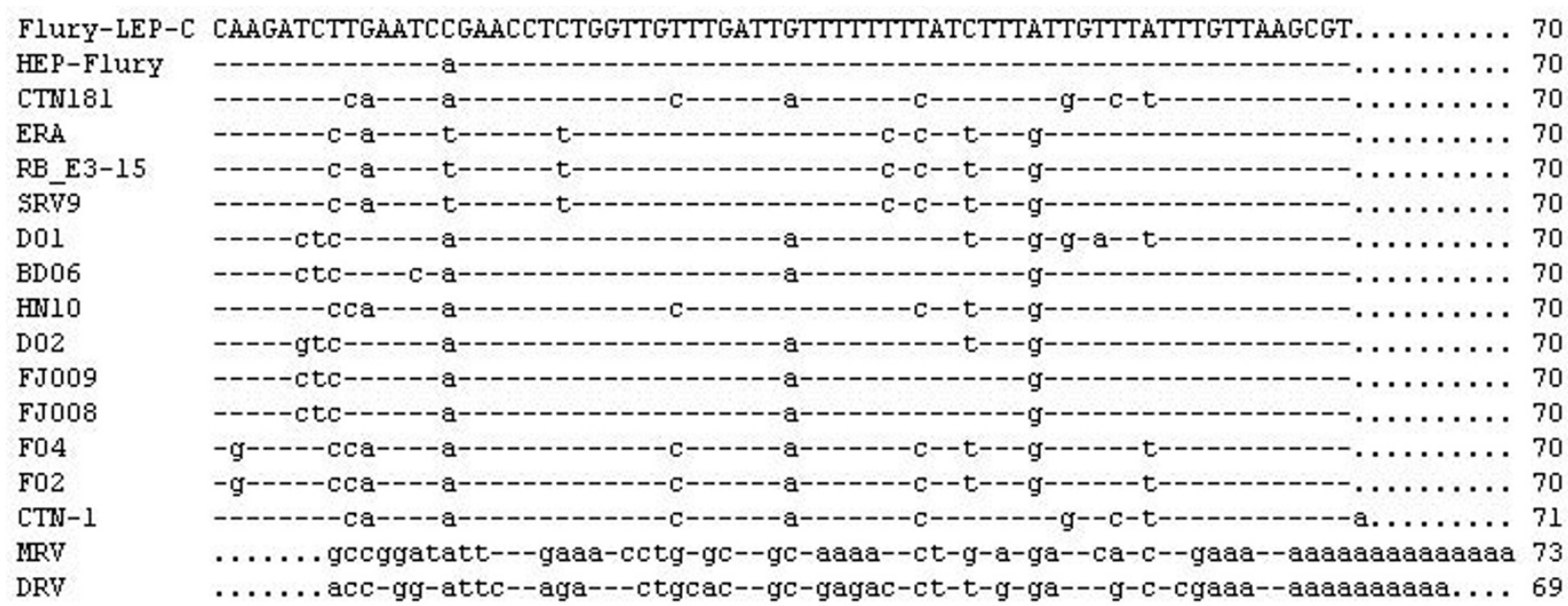

Figure 2 Comparison of 5 '-termini of the antigenome (+) sense RNA (in DNA code). 5'-termini of Flury-LEP-C strain and other rabies virus were compared. Only differences from the reference sequences are shown. "-" indicate sequence identity to the reference sequence and a "." indicate missing sequence. 


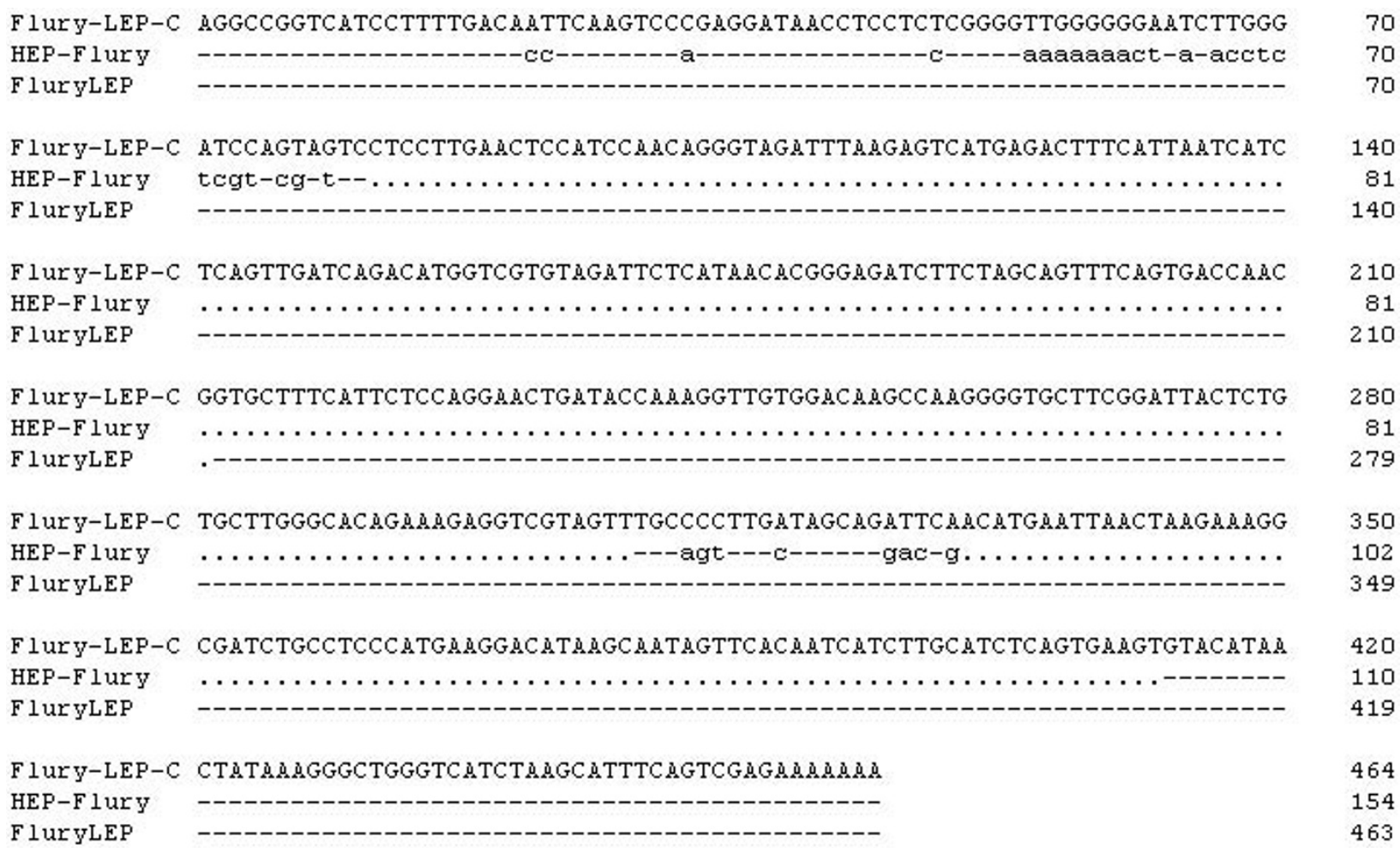

F lurY-LEP-C ATCCAGTAGTCCTCCTTGÄCTCCATCCÄCAGGGTAGATTTÄGAGTCATGAGACTTTCATTÄTCATC

Figure 3 Nucleotide acid sequence alignment of the non-coding G-L region of Flury-LEP-C, Flury LEP and HEP-Flury. "-" indicate sequence identity to the reference sequence and a "." indicate missing sequence.

sequence in the end of the non-coding G-L region. There were AACAYYYCT consensus start signal close to the $\mathrm{TGA}_{7}$. The main difference between Flury LEP and Flury-LEP-C was that the latter has $12 \mathrm{nt}$ more than the former in L gene (Table 3). Further studies are necessary to elucidate the role of these mutations in Flury-LEP-C.

The entire amino acid sequence of Flury-LEP-C was aligned with 17 entire genome sequences (as shown in table 2) obtained from the GenBank. Analysis of deduced amino acid sequences from open reading frames (ORFs) of N, P, M, G, and L genes revealed 98.81\%, 93.94\%, $96.75 \%, 95.12 \%, 97.69 \%$. Szanto reported that $\mathrm{P}$ gene was the most variable gene[11], similar result was obtained in Flury-LEP-C.

The $\mathrm{G}$ gene does indeed encode a product of 524 amino acids but this includes a 19 amino acid $\mathrm{N}$-terminal signal peptide that is cleaved to generate the mature product of 505 amino acids. It was reported that the $\mathrm{G}$ protein plays an important role in viral pathogenicity and protective immunity, especially residue Arg333 [1,12-17]. Jackson et al. reported that less neurovirulent strain, which contains an attenuating substitution of Arg333 in the rabies virus glycoprotein, was a stronger inducer of neuronal apoptosis and there was an inverse relationship between patho- genicity and apoptosis [18]. In this study, the analysis showed that the residue at 333 of the mature G protein was Arg.

$\mathrm{P}$ protein is a structural component of the RNP. And $\mathrm{P}$ protein is also crucially involved in numerous events during the virus life cycle, including proper formation of viral RNPs and virus particles and viral RNA synthesis [14]. The P protein has been shown to interact with LC8 (cytoplasmic dynein light chain) at residues 138-172 [19,20], specifically the motif K/RXTQT at residues 145-149 [20]. Mebatsion found that the deletions introduced into the LC8 binding site abolished the P-LC8 interaction, blocked LC8 incorporation into virions, and reduced the efficiency of peripheral spread of the virus, but LC8 is dispensable for the spread of a pathogenic RV from a peripheral site to the CNS [19]. We found that the minimal binding motif for LC8 at residues 145-149 of P protein was KSTQT in all rabies sequences in this study, except that SHBRV-18 has a KATQT motif.

Compared with FluryLEP, there were 19 different amino acids (AAs) in five proteins of Flury-LEP-C, including 15 AAs which were identical with corresponding residues of Hep-Flury, and 4 AAs which were neither identical with the residues of FluryLEP nor with the resi- 
Table 3: Different proteins of Flury-LEP-C compared with FluryLEP and Hep-Flury strains.

\begin{tabular}{llll}
\hline Protein & FluryLEP & Flury-LEP-C & Hep-Flury \\
\hline N & Y288 & H288 & H288 \\
P & D59 & G59 & D59 \\
& F115 & L115 & L115 \\
& L186 & W186 & W186 \\
& K231 & E231 & E231 \\
M & A22 & V22 & A22 \\
G & V13 & G13 & V13 \\
& H283 & R283 & R283 \\
& Q297 & K297 & K297 \\
& E368 & G368 & E368 \\
& Y371 & H371 & H371 \\
& 1415 & M415 & M415 \\
& T510 & I510 & I510 \\
& & Y166 & Y166 \\
& & L167 & L167 \\
& & D387 & D387 \\
& N387 & V450 & V450 \\
& 1450 & N833 & N833 \\
& & A834 & A834 \\
& & & \\
& & &
\end{tabular}

dues of Hep-Flury (table 3). Comparison of L protein of all RVs in table 2 showed that all RVs, except Hep-Flury and FluryLEP, have these four insertions in $\mathrm{L}$ protein. Studies are undertaking to find difference in phenotypic characteristics between the Flury-LEP-C and its parental strain FluryLEP.

In this study, two kinds of proteins were used to construct the phylogeny tree. First, nucleotide sequences of five viral genes of each strain were translated into protein sequences and joined to one sequence in the original order, based on which a phylogenetic tree was generate (Fig. 4). Second, P protein, due to its multifunctional nature including its ability to interact with host-cell proteins [21], were also used to construct a phylogeny tree (Fig. 5). The results showed the topology of the phylogenetic trees generated by these two methods were similar. It was demonstrated that HN10, BD06, FJ009, FJ008, D02, D01, F04, F02 have a close relationship to CTN-1 and CTN181, which means the homology between the CTN stains and the Chinese street strains was much higher than that of any other vaccine strain. And MRV was closely related to Flury-LEP, HEP-Flury and Flury-LEP-C, but DRV formed an outlying clade. The CTN (or its derivates, including CTN-1 and CTN181), PV and PM strains are the human rabies virus vaccine strains, and FluryLEP,

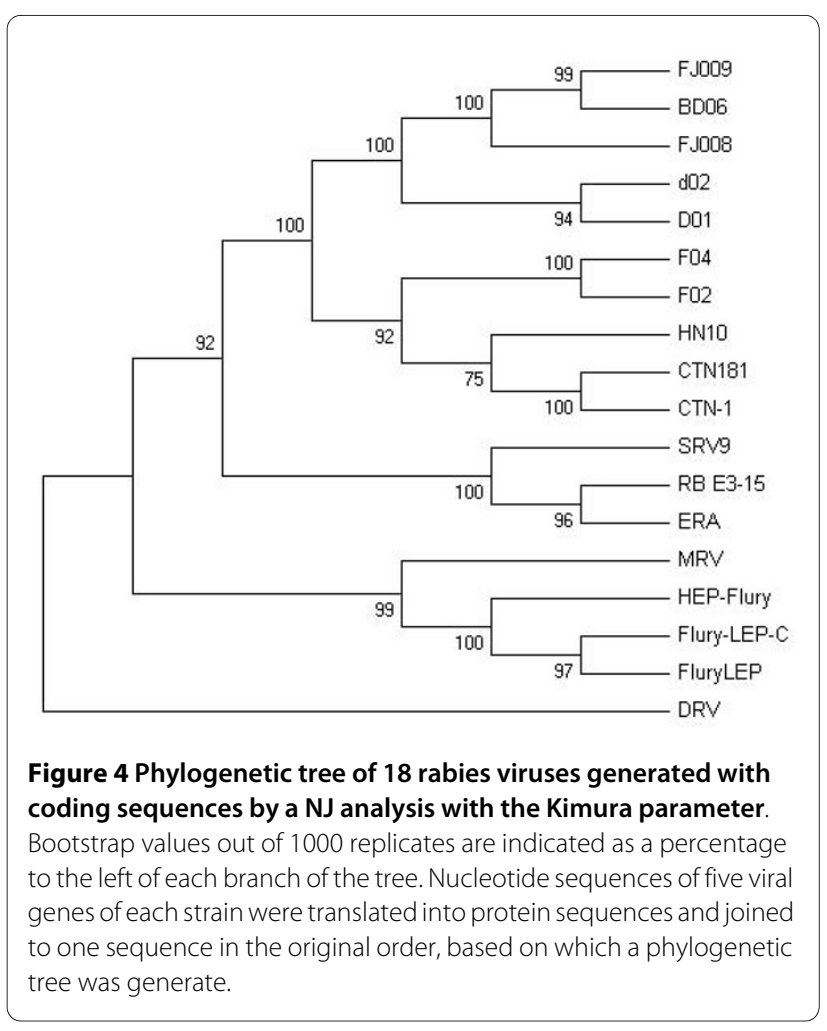

HEP-Flury, ERA and CTN-1 are the veterinary rabies virus vaccine strains currently used in China. It was hypothesized the CTN strain should be most suitable for use in China as a vaccine strain [10,22], and the result in our study also supported the hypothesis.

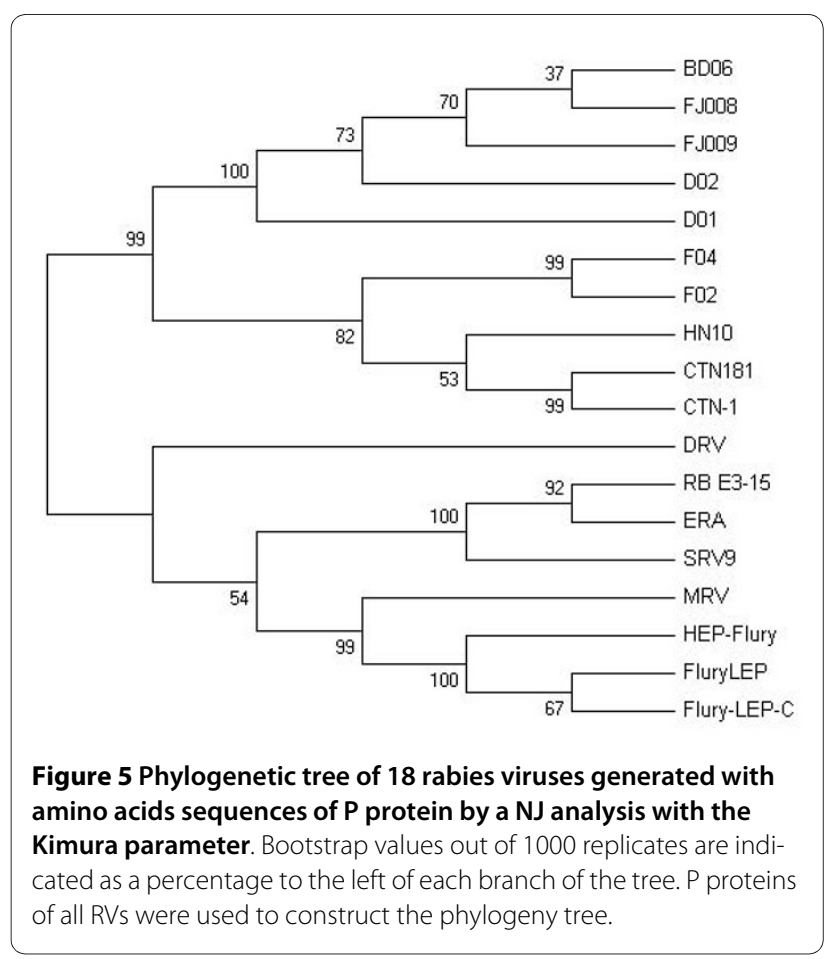




\section{List of abbreviations}

RACE: rapid amplification of cDNA ends; RV: rabies virus; RT-PCR: Reverse transcription polymerase chain reaction; RNP: ribonucleoprotein.

\section{Competing interests}

The author declares that they have no competing interests.

\section{Authors' contributions}

The author has made substantial contributions to design, acquisition of data analysis and interpretation of data, and draft the manuscript.

\section{Acknowledgements}

This work was financially supported by department of science and technology of Heping campus, Jilin University, China. The author would like to thank Professor Hongsheng Ouyang at the College of Animal Science and Veterinary Medicine, Jilin University, for his support.

\section{Author Details}

College of Animal Science and Veterinary Medicine, Jilin University, Changchun 130062 , China

Received: 8 March 2010 Accepted: 28 April 2010

Published: 28 April 2010

\section{References}

1. Metlin A, Paulin L, Suomalainen S, Neuvonen E, Rybakov S, Mikhalishin V, Huovilainen A: Characterization of Russian rabies virus vaccine strain RV-97. Virus Research 2008, 132(1-2):242-247.

2. Liu Q, Xiong Y, Luo TR, Wei YC, Nan SJ, Liu F, Pan Y, Feng L, Zhu W, Liu K, Guo JG, Li HM: Molecular epidemiology of rabies in Guangxi Province, south of China. Journal of Clinical Virology 2007, 39:295-303.

3. Tang Q, Li H: Epidemic situation and related factors analyses of rabies in China. Chinese Journal of Epidemiology 2005, 26:223-224.

4. Zhang YZ, Xiong CL, Xiao DL, Jiang RJ, Wang ZX, Zhang LZ, Fu ZF: Human rabies in China. Emerging Infectious Diseases 2005, 11(12):1983-1984.

5. Ministry of health of the PRC, The ministry of Public security of the PRC, Ministry of agriculture of the PRC, The State food and drug administration: Progress of prevention and cure of rabies in China. Progress report. Beijing, China 2009.

6. Blanton JD, Self J, Niezgoda M, Faber ML, Dietzschold B, Rupprecht C: Oral vaccination of raccoons (Procyon lotor) with genetically modified rabies virus vaccines. Vaccine 2007, 25(42):7296-7300

7. Pastoret PP, Brochier B: Epidemiology and control of fox rabies in Europe. Vaccine 1999, 17:1750-1754.

8. Meng SL, Yan JX, Xu GL, Nadin-Davis SA, Ming PG, Liu SY, Ming HT, Zhu FC, Zhou DJ, Xiao QY, Dong GM, Yang XM: A molecular epidemiological study targeting the glycoprotein gene of rabies virus isolates from China. Virus Research 2007, 124:125-138.

9. Marston DA, McElhinney LM, Johnson N, Muller T, Conzelmann KK, Tordo N, Fooks AR: Comparative analysis of the full genome sequence of European bat lyssavirus type 1 and type 2 with other lyssaviruses and evidence for a conserved transcription termination and polyadenylation motif in the G-L 3' non-translated region. Journal of General Virology 2007, 88:1302-1314

10. Meng SL, Xu GL, Yan JX, Ming PG, Wu J, Yang XM, Ming HT, Zhu FC, Zhou DJ, Xiao QY, Dong GM: Molecular epidemiology and sequencing of the $\mathrm{G}-\mathrm{L}$ intergenic region of rabies viruses isolated in China. Virologica Sinica 2007, 22(1):26-33

11. Szanto AG, Nadin-Davis SA, White BN: Complete genome sequence of a raccoon rabies virus isolate. Virus Research 2008, 136(1-2):130-139.

12. Cox JH, Dietzschold B, Schneider LG: Rabies virus glycoprotein. II. Biological and serological characterization. Infection and Immunity 1977, 16:754-759.

13. Dietzschold B, Wunner WH, Wiktor TJ, Lopes AD, Lafon M, Smith C, Koprowski $\mathrm{H}$ : Characterization of an antigenic determinant of the glycoprotein that correlates with pathogenicity of rabies virus. Proceedings of the National Academy of Sciences 1983, 80:70-74

14. Faber M, Faber ML, Papaneri A, Bette M, Weihe E, Dietzschold B, Schnell MJ: A single amino acid change in rabies virus glycoprotein increases virus spread and enhances virus pathogenicity. Journal of Virology 2005, 79(22):14141-14148.

15. Morimoto K, Foley HD, McGettigan JP, Schnell MJ, Dietzschold B: Reinvestigation of the role of the rabies virus glycoprotein in viral pathogenesis using a reverse genetics approach. Journal of Neurovirology 2000, 6:373-381.

16. Seif I, Coulon P, Rollin PE, Flamand A: Rabies virulence: effect on pathogenicity and sequence characterization of rabies virus mutations affecting antigenic site III of the glycoprotein. Journal of Virology 1985, 53:926-934

17. Yelverton E, Norton S, Obijeski JF, Goeddel DV: Rabies virus glycoprotein analogs: biosynthesis in Escherichia coli. Science 1983, 219(4585):614-620

18. Jackson AC, Rasalingam P, Weli SC: Comparative pathogenesis of recombinant rabies vaccine strain SAD-L16 and SAD-D29 with replacement of Arg333 in the glycoprotein after peripheral inoculation of neonatal mice: less neurovirulent strain is a stronger inducer of neuronal apoptosis. Acta Neuropathologica 2006, 111(4):372-378.

19. Mebatsion T: Extensive attenuation of rabies virus by simultaneously modifying the dynein light chain binding site in the $\mathrm{P}$ protein and replacing Arg333 in the G protein. Journal of Virology 2001, 75(23):11496-11502.

20. Lo KW, Naisbitt S, Fan JS, Sheng M, Zhang M: The 8-kDa dynein light chain binds to its targets via a conserved (K/R)XTQT motif. The Journal of Biology and Chemistry 2001, 276:14059-14066.

21. Poisson N, Real E, Gaudin Y, Vaney MC, King S, Jacob Y, Tordo N, Blondel D: Molecular basis for the interaction between rabies virus phosphoprotein $\mathrm{P}$ and the dynein light chain LC8: dissociation of dynein-binding properties and transcriptional functionality of $P$. Journal of General Virology 2001, 82:2691-2696.

22. Meng SL, Xu GL, Wu J, Yang XM, Yan JX: A comparison of complete genome sequences of a rabies virus Chinese isolate $\mathrm{SH} 06$ with the vaccine strains. Virologica Sinica 2009, 24(6):529-536.

doi: $10.1186 / 1743-422 X-7-80$

Cite this article as: Ren, Molecular characterization of a Chinese variant of the Flury-LEP strain Virology Journal 2010, 7:80

\section{Submit your next manuscript to BioMed Central and take full advantage of:}

- Convenient online submission

- Thorough peer review

- No space constraints or color figure charges

- Immediate publication on acceptance

- Inclusion in PubMed, CAS, Scopus and Google Scholar

- Research which is freely available for redistribution 